\title{
SCIDiC
}

\author{
International Journal of Dentistry and Oral Science (IJDOS) \\ ISSN: 2377-8075
}

\section{Williams Syndrome: Oral Findings and Orthodontic Management of a Rare Disease}

Case Report

Alessandra Putrino $^{1 *}$, Altieri Federica ${ }^{2}$, Giovannoni Denise ${ }^{3}$, Di Giorgio Roberto ${ }^{4}$, Barbato Ersilia ${ }^{5}$, Galluccio Gabriella $^{6}$, Cassetta Michele

1,2 DDS, Specialist in Orthodontics, PhD Researcher, Department of Oral and Maxillofacial Sciences, Sapienza University of Rome, Italy.

${ }^{3}$ A DDS, Specialist in Orthodontics, Postgraduate School in Orthodontics, Unit of Orthodontics, Department of Oral and Maxillofacial Sciences, Sapienza University of Rome, Italy.

${ }^{4}$ Associate Professor, Unit of Orthodontics, Department of Oral and Maxillofacial Sciences, Sapienza University of Rome, Italy.

${ }^{5}$ Full Professor, Postgraduate School in Orthodontics, Unit of Orthodontics, Department of Oral and Maxillofacial Sciences, Sapienza University of Rome, Italy.

${ }^{6}$ Associate Professor, Postgraduate School in Orthodontics, Unit of Orthodontics, Department of Oral and Maxillofacial Sciences, Sapienza University of Rome, Italy.

${ }^{7}$ Associate Professor, Postgraduate School in Orthodontics, Unit of Orthodontics, Department of Oral and Maxillofacial Sciences, Sapienza University of Rome, Italy.

Abstract

The rare genetic disorder called Williams syndrome is due to microdeletion of long arm of chromosome 7 with defect of 20 genes including the one encodes for elastine. Haploinsufficiency characterizes this syndrome causing effects on many organs. Patients have severe heart diseases, kidney disorders, diseases of the digestive system on hereditary basis, psycho-motor delay, specific behavioral/cognitive profile and typical facial dysmorphism (elphic face) and oral anomalies (micrognathism, hypodontia, severe crowding or diastemas, irregular shapes of teeth and dental arches, enamel defects). The orthodontic case of a 14 years old boy affected by the syndrome is reported. The combination of different fixed orthodontic appliances allowed to correct many aspects of his malocclusion: narrow palate, severe crowding, crossbites. The patient greatly improved his dental and functional situation with significant changes also from a cephalometric point of view. The psychological characteristics of this syndrome, in addition to problems arising from other organs disorders that can complicate adherence to therapy, requires an approach very calm and empathetic because not always all sessions find the patient collaborative. Despite difficulties and therapeutic compromises that must be accepted, treating orthodontically these patients is worthwhile to improve the health conditions of their oral cavity.

Keywords: Williams Syndrome; Orthodontics, Genetics; Dento-Skeletal Anomalies.

\section{Introduction}

The rare genetic disorder known as Williams syndrome (WS), also called Williams-Beuren syndrome (WBS; OMIM \#194050) or Infantile Hypercalcaemia, has been described for the first time in 1952 [1] as "idiopathic infantile hypercalcaemia with failure to thrive", but it owes its name to Drs. J.C. Williams and A.J. Beuren that documented cases with aortic stenosis and mental retardation and typical facial appearance about ten years later [2]. The genetic mapping for this syndrome was obtained in the 1990s. A microdeletion of the long arm of chromosome 7 which causes the loss of about 20 genes including the one encoding elastin, called the "marker gene" and domain kinase 1 (LIMK1) [3]. The prevalence is one on in every 7500 live births [2]. The haploinsufficiency that characterizes this syndrome causes it to manifest itself with effects on different organs. They are associated in $75 \%$ of cases of heart disease (usually overpowering stenosis of the aorta, strictures of the renal aorta that can cause reno-vascular arterial hypertension), psycho-motor delay, facial dysmorphism and specific behavioral and cognitive profile. The cognitive profile is characterized by visuo-spatial deficits, which contrasts with good language skills. Affected children exhibit hypersocial behavior and

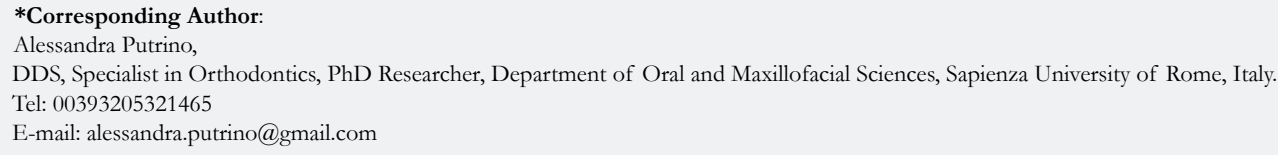

Citation: Alessandra Putrino, Altieri Federica, Giovannoni Denise, Di Giorgio Roberto, Barbato Ersilia, Galluccio Gabriella, et. al. Williams Syndrome: Oral Findings and Orthodontic Management of a Rare Disease. Int J Dentistry Oral Sci. 2021;8(8):3690-3694. doi: http://dx.doi.org/10.19070/2377-8075-21000756

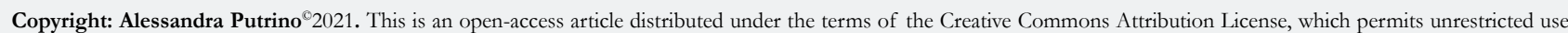
distribution and reproduction in any medium, provided the original author and source are credited. 
interact well with other people. They are very sensitive to noise and have good musical skills. From an ophthalmological point of view, strabismus and/or refraction defects are common. Diagnosis cannot be detected with the standard cariotype but must be revealed with FISH (hybridization in situ fluorescent) which has a specific reliability of $95 \%$ [4]. Vascular malformations require regular follow-up and specific therapies under the control of a pediatric cardiologist. The face has a characteristic appearance: flattened nasal septum and globian nose tip, wide mouth, with anteverse lower lip, prominent cheeks, periorbital edema, epicanto and, often, the "star" iris. As the face grew, it becomes narrower and takes on coarse features. From an oral point of view, subjects frequently have malocclusions with micrognathism, dental arches with irregular forms, severe dental crowding or diastemas, hypodontia, microdontia, enamel defects, dental shape abnormalities [5]. In Italy, there are currently fewer than three thousand cases [6]. The majority of cases in the dental literature are limited to describing the oral characteristics of the syndrome without documenting any treatment $[4,6-9]$.

\section{Case Report}

A 14 years old boy affected by the WBS started orthodontic therapy after undergoing the specialistic visit in the Unit of Orthodontics and evaluating the pros and cons of the treatment together with the other specialist who followed the patient in a multidisciplinary form (including cardiologist, pediatrician, psychologist, speech therapist and gastroenterologist). The parents signed informed consent authorizing the use of the son's data anonimously to document the individual characteristics of the syndrome and data relating to therapy (including the publication of his photos and radiographs in respect the patient's privacy). The documentation of this case for educational scientific research purposes is included in the approval of the Ethics Committee of the Policlinico Umberto I Hospital of Rome- "Sapienza" University for "the study of cranial anatomy and its anomalies" n'4663. The patient presented heart problems and high blood pressure farmacologically compensated with a combination of candesartan/ hydroclorotiazide. His congenital heart valvular defect required a first cardiosurgery operation at 7 years old. He was affected by the celiac disease too so he followed a gluten free diet. He had also a chronic renal failure due to a deformation of the right kidney to which is added a reno-vascular arterial hypertension. From an orthodontic point of view the patient showed a normofacial type, with a convex profile and a symmetrical face whose exception was a slight right eye squint. The face shows the others typical features of the syndrome: the flattened nasal septum and globian nose tip, the anteverse nostrils, the wide mouth with full lips and anteverse lower lip, the prominent cheeks, the periorbital edema, the epicanto and the star iris (Figure 1). The intraoral examination showed a mixed dentition with a severe crowding in the lower arch and narrow shape in the upper arch. The patient had a I class molar on both sides and a not valuable canine class. The presence of deep bite hid the upper midline was deflected to the right and the lower midline was deflected to the left. Some crossbites were present: the 2.2 on the 7.2 , the 6.3 on the 7.3 and the 2.4 on on the 3.4. From an occlusal view, in addition to making evident the deformities of both arches, despite the presence of the ccorresponding deciduous teeth, the teeth 2.3, 3.2 and 4.4 are erupted and the clinic crown of 2.3 and 3.2 are the first ectopic (2.3 in place of 2.4) in abnormal buccal position and the second in lingual position (Figure 2). The first ortopantomograph (Figure 3) showed the agenesis of the four second premolars and confirmed the transposition of 2.3 on 2.4. The cephalometric analysis in lateral view pointed out the patient is a first skeletal class with a slight hyperdivergence, reduced size of the mandibular body, tendency for mandibular growth in clockwise rotation, proclined incisors, reduced interincisor angle (Figure 4, Table 1). The treatment plan was divided into several phases: Initially a dento-alveolar expansion action was planned with quad helix cemented on the first upper molars and management of the lower crowding with the lingual arch also cemented on the first molars. After reaching a good level of results with these appliances (11 months) allowed to manage successfully the cross-bite and crowding, fixed multibrackets therapy was added on both arches (MBT prescription) to align and level the teeth, correct the position of the strongly misplaced elements and intervene on the transposition. During the therapy it was not always possible to carry out activations at each session because the patient's sensitivity and his predisposition to stress linked to external factors meant that he did not always willingly accept being controlled. Despite this, the patient has always enthusiastically accepted to go to periodic check-ups, transforming the sessions in which he was not willing to do the checks into moments of game with the operators who went along with his needs and respected his times. It was extremely important to guide the patient, supported by the mother, towards greater responsibility in the control of oral hygiene, which had been significantly improved since the beginning of therapy. During the phases of multibrackets therapy, the patient did not want to undergo

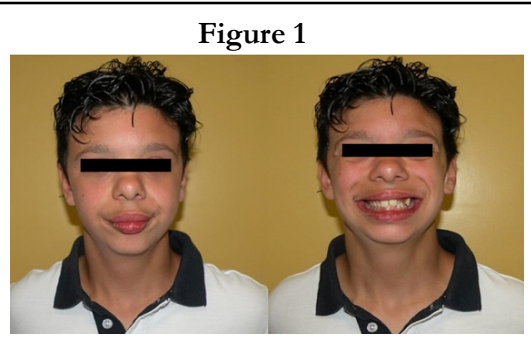

Figure 3

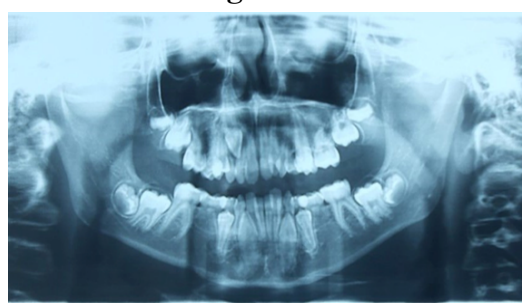

Figure 2

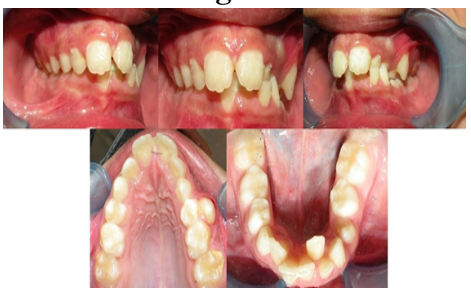

Figure 4

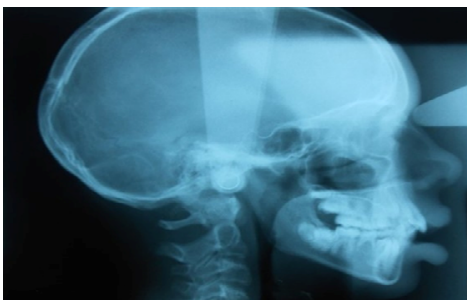


the detection of new photographic records which for him were a cause of great anxiety and concern despite the repeated explanations on how they were performed and the importance of doing so. After three and a half years from the beginning of the therapy, the patient had to interrupt the orthodontic therapy to have to undergo a new cardio-surgical intervention. Aware of the need to continue orthodontic therapy, it was decided with the parents to remove the appliance, however more than satisfied with the results currently achieved (Figures 5 and 6). New radiographs were requested to evaluate the results obtained and the overall situation and reassess the case pending a possible resumption of therapy (Figures 7 and 8). By observing the orthopantomograph it is possible to observe that the patient has finished the dental exchange, the second molars are erupted and the third molars, more structured at the root level, require a surgical evaluation to assess possible need for extraction (in particular for the dental elements 1.8, 3.8 and 4.8). The roots of the deciduous teeth interested by the agenesis of their permanent elements, which were not involved in the multibracket therapy, are very reabsorbed and as confirmed by the clinical examination, the element 5.5 would need extraction given its position and mobility. Cephalometric analysis on the post treatment laterolateral teleradiograph showed the manteinance of a first skeletal class with an improvement of the interincisive angle and a better position of the upper incisors. The other parameters slightly changed and some of them probably were modified for the growth and not for the therapy (Figure 8, Table 1).

\section{Discussion}

The Williams-Beuren syndrome is characterized by developmental and physical abnormalities due to the hemizygous deletion of a wide number of continuous genes including elastin (ELN) and LIM domain kinase 1 (LIMK1) on the chromosome 7q11.23 [3]. This is the reason leads to have patients with multi-systemic alterations require a multidisciplinary approach. The phenotypic variability and the broad spectrum of anomalies may undermine the diagnosis also because the syndrome can be transmitted with autosomal inheritance but most of the cases are sporadic [2]. The dento-skeletal characteristics are typical indeed all the studies documenting the facial dysmorphism of the syndrome describe the same features: wide mouth, micrognathism, malocclusion, hypodontia, microdontia and abnormal tooth morphology $[5,7,9]$. Oral abnormalities appear since the early age, rarely they are not evident after the first year of life [8]. Our patient presented features comparable to those documented in the other studies and other different and exclusive ones. Infact while from the extraoral examination the features followed in all those of the so-called "elfin face" [6], the intra-oral situation presented contrasting elements with those of the similar studies on the syndrome. The intraoral aspects common to those already described in the literature were: the presence of diffuse diastemas, the anomalies of the shape of the teeth, the agenesis of multiple teeth, the deformities of the arches. Recent studies report diffuse diastemas is frequent and often joined to a high arched palate [10]. This last feature is in opposition with the situation of our patient that had a contracted palate with diastemas and a severe crowding in the lower dental arch. In our patient is evident a general microdontia even if we cannot in addition term them as screwdriver or affected by taurodontism teeth as documented in other studies [5, 7]. The four second premolars are missing for agenesis and this is in agreement with other studies state second premolars are the most frequently missing teeth in these patients (followed by mandibular lateral incisors) [8]. No other skeletal anomalies associated to dental agenesis in syndromic or non-syndromic patients have been found on the lateral cephalogram $[11,12]$. Both the dental arches had an abnormal shape and their correction has been gained more easily in the upper arch than in the lower arch. On the vertical plane, most of the studies describe cases of subjects with open bites whose establishment is favoured by macroglossia and incorrect position of the tongue at rest and at a functional level [2, 5 - 7]. In literature cases of Williams syndrome with open bite are widely described $[5,7,8,10,11]$, while our patient had a malocclusion characterized by a deep bite. The presence of a dental transposition as observed in the case described in our article has not been found in literature as typical oral finding in other patients with Williams syndrome. Some studies document the syndrome from an epidemiological point of view with respect to the incidence of carious lesions and missing teeth because they have been extracted or treated according to conservative principles [3, 10]. Although our patient did not have good initial oral hygiene (a
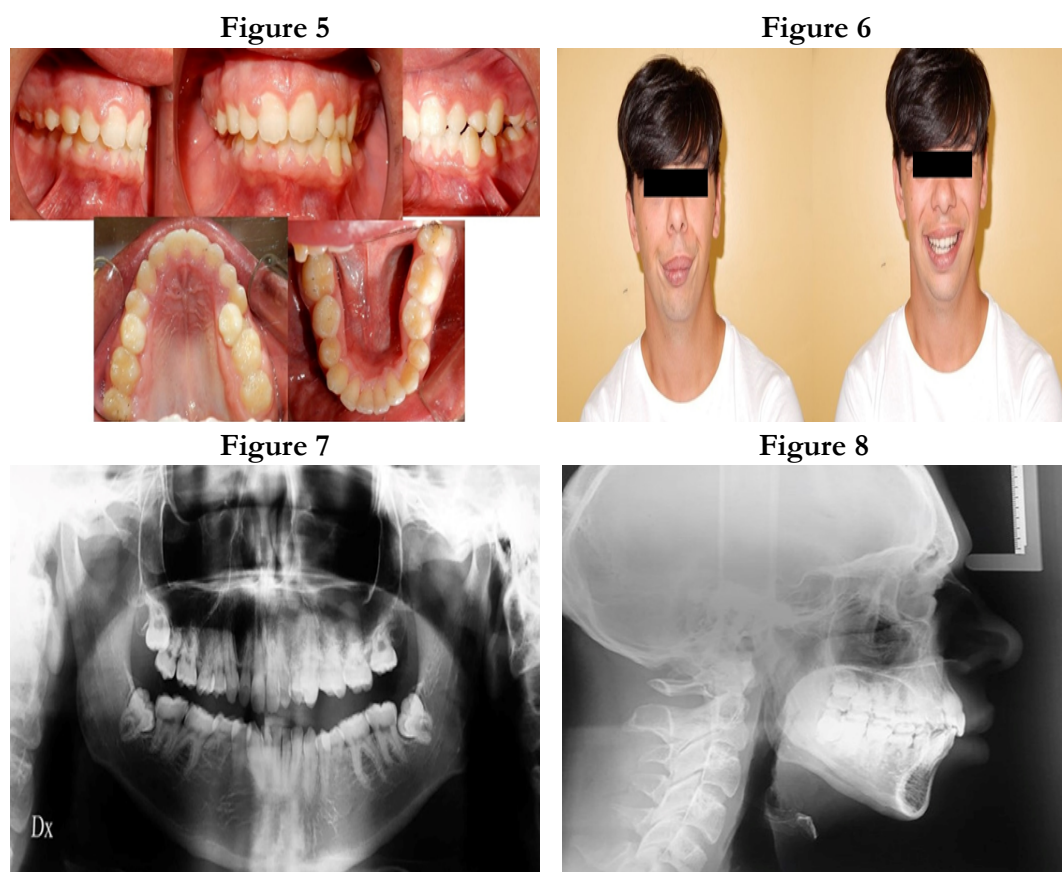

Alessandra Putrino, Altieri Federica, Giovannoni Denise, Di Giorgio Roberto, Barbato Ersilia, Galluccio Gabriella, et. al. Williams Syndrome: Oral Findings and Orthodontic Management of a 
Table 1: Cephalometric values pre-treatment (First Cephalogram) and post-treatment (Second Cephalogram) with changes for each measurement.

\begin{tabular}{|c|c|c|c|}
\hline Cephalometric values & First cephalogram & Second cephalogram & Changes \\
\hline $\mathrm{SNA}^{\circ}$ & 82.9 & 80.6 & 2.3 \\
\hline $\mathrm{SNB}^{\circ}$ & 81.5 & 81.4 & 0.1 \\
\hline $\mathrm{ANB}^{\circ}$ & 1.4 & 0.8 & 0.6 \\
\hline $\mathrm{SNPog}^{\circ}$ & 80.7 & 80.2 & 0.5 \\
\hline Pog to NB (mm) & -0.9 & -2.2 & 1.3 \\
\hline Wits (mm) & -0.4 & -1.1 & 0.7 \\
\hline Occlusal to $\mathrm{SN}^{\circ}$ & 9.9 & 13.9 & 4 \\
\hline $\mathrm{SN}$ to $\mathrm{GoGn}{ }^{\circ}$ & 28.1 & 29.2 & 1.1 \\
\hline Upper Incisor to $\mathrm{NA}^{\circ}$ & 25.7 & 12.4 & 13.3 \\
\hline Upper Incisor to NA (mm) & 6 & 4.5 & 1.5 \\
\hline Lower Incisor to $\mathrm{NB}^{\circ}$ & 28.1 & 30.2 & 2.1 \\
\hline Lower Incisor to NB (mm) & 3.9 & 6.3 & 2.4 \\
\hline Interincisive Angle $^{\circ}$ & 125.7 & 134.1 & 8.4 \\
\hline Lower Incisor to GoGn ${ }^{\circ}$ & 98.5 & 90.6 & 7.9 \\
\hline Overjet $(\mathrm{mm})$ & 2.5 & 2.6 & 0.1 \\
\hline Overbite (mm) & 3.5 & 2.2 & 1.3 \\
\hline FMA $^{\circ}$ & 24.5 & 23.6 & 0.9 \\
\hline FMIA $^{\circ}$ & 58.7 & 59.3 & 0.6 \\
\hline IMPA $^{\circ}$ & 96.8 & 97.1 & 0.3 \\
\hline $\mathrm{NSAr}^{\circ}$ & 122.2 & 126.3 & 4.1 \\
\hline $\mathrm{SArGo}^{\circ}$ & 132 & 139.9 & 7.9 \\
\hline $\mathrm{ArGoMe}^{\circ}$ & 135.6 & 125.5 & 10.1 \\
\hline Bjork sum & 389.8 & 391.7 & 1.9 \\
\hline Posterior Face Height (mm) & 58.3 & 73.4 & 15.1 \\
\hline Anterior Face Height (mm) & 68.9 & 105.6 & 36.7 \\
\hline Facial Height Index & $70.10 \%$ & $69.50 \%$ & 0.6 \\
\hline $\mathrm{SN}$ to $\mathrm{GoMe}^{\circ}$ & 29.8 & 31.7 & 1.9 \\
\hline Upper Incisor to $\mathrm{SN}^{\circ}$ & 107.7 & 97 & 10.7 \\
\hline $\begin{array}{c}\text { Upper Incisor to Facial } \\
\text { Plane (mm) }\end{array}$ & 7 & 10.1 & 3.1 \\
\hline Lower Incisor to GoMe ${ }^{\circ}$ & 96.8 & 97.1 & 0.3 \\
\hline $\begin{array}{c}\text { Lower Incisor to Facial } \\
\text { Plane }(\mathrm{mm})\end{array}$ & 4.5 & 7.7 & 3.2 \\
\hline A to $\mathrm{N}$ perp. & -1.5 & 2.3 & -3.8 \\
\hline Pog to N perp. & -4.6 & -2.9 & -1.7 \\
\hline Upper Incisor to A perp. & 5.5 & 5.8 & 0.3 \\
\hline Lower Incisor to A-Pog & 4.1 & 5.5 & 1.4 \\
\hline
\end{tabular}

level which improved during the course of orthodontic therapy thanks to the collaboration of dental hygienists), he did not have carious lesions nor he had ever undergone conservative sessions for the treatment of any decayed tooth. No teeth were extracted for destructive carious lesions and the only teeth absent were the permanent ones affected by agenesis. Another study focuses on any periodontal abnormalities that could result from the elastin defect in this syndrome [13]. The patient documented in our case has only gingival problems due to poor and ineffective brushing and plaque accumulation, but from a periodontal point of view, no signs compatible with periodontal suffering are evident either clinically or radiographically. The second orthopantomograph shows an abnormal eruptive pattern and position of the third molars and their extraction will be evaluated later in agreement with the cardiologist following the recent principles of third molars surgery after orthodontic treatment. Cephalometrically, in the previous studies patients almost always appear as skeletal third class $\left(<0^{\circ} \mathrm{ANB}\right.$ angle), hyperdivergent $\left(>25 \pm 1^{\circ}\right)$, with open bite, increased skull base width $\left(>135^{\circ} \mathrm{NSBa}\right.$ angle) and sella turcica anomalies [5, 6, $9-11]$. Our patient started the treatment as a skeletal first class, normodivergent and with a deep bite. No signs of anomalies in the sella turcica were detected on the lateral cephalogram nor increased skull base witdth values. About the orthodontic treatment on patients affected by the syndrome, the only studies to treat this topic available in literature are cases approached in a surgical orthodontic-way due to the extreme sever- 
ity of the malocclusions of their patients $[11,15]$. In our case, the orthodontic need was managed through a fixed therapy combined with Quad Helix, lingual arch and multibracket therapy due to the malocclusion did not require more invasive interventions.

\section{Conclusion}

Williams-Beuren syndrome presents a wide variability of oral manifestations from the point of malocclusions. The classification of these patients for orthodontic diagnosis allows, except for limitations related to their general health conditions, to improve, with the appropriate interventions, the patient's quality of life in functional terms and also with significant psychological implications.

\section{References}

[1]. Fanconi G, Girardet P, Schlesinger B, Butler N, Black J. Chronic hyperglicemia, combined with osteosclerosis, hyperazotemia, nanism and congenital malformations. Helv Paediatr Acta. 1952; 7: 314-349.Pubmed PMID: 12980492

[2]. Joyce CA, Zorich B, Pike SJ, Barber JC, Dennis NR. Williams-Beuren syndrome: phenotypic variability and deletions of chromosomes 7,11 , and 22 in a series of 52 patients. J Med Genet. 1996 Dec;33(12):986-92. Pubmed PMID: 9004128.

[3]. Patil S, Rao RS, Majumdar B. Chromosomal and multifactorial genetic disorders with oral manifestations. J Int Oral Health. 2014 Sep;6(5):118-25. Pubmed PMID: 25395808.

[4]. Gilbert-Dussardier B. Le syndrome de Williams-Beuren [Williams-Beuren syndrome]. Rev Prat. 2006 Dec 15;56(19):2102-6. French. Pubmed PMID: 17416045

[5]. Axelsson S, Kjaer I, Heiberg A, Bjørnland T, Storhaug K. Neurocranial morphology and growth in Williams syndrome. Eur J Orthod. 2005 Feb;27(1):32-47. Pubmed PMID: 15743861.
[6]. Maurino V, Azzi L, Vinci R, Croveri F, Boggio A, Silvestre-Rangil J, Tettamanti L, Tagliabue A. The 囚elfin face区: craniofacial and dental aspects of the Williams-Beuren syndrome. J Biol Regul Homeost Agents. 2017 AprJun;31(2 Suppl 1):105-111. Pubmed PMID: 28691460.

[7]. Cingano L, Servetto R, Loria P, Calcagno E. Odontostomatological aspects in patients with Williams syndrome: a series of 4 cases. Minerva Stomatol. 2013 Nov-Dec;62(11-12):447-54. Pubmed PMID: 24172828.

[8]. Ferreira SB, Viana MM, Maia NG, Leấo LL, Machado RA, Coletta RD, de Aguiar MJ, Martelli-Júnior H. Oral findings in Williams-Beuren syndrome. Med Oral Patol Oral Cir Bucal. 2018 Jan 1;23(1):e1-e6. Pubmed PMID: 29274148.

[9]. Matsuno S, Tsuji M, Hikita R, Matsumoto T, Baba Y, Moriyama K. Clinical study of dentocraniofacial characteristics in patients with Williams syndrome. Congenit Anom (Kyoto). 2019 Sep;59(5):162-168. Pubmed PMID: 30315601 .

[10]. Tarjan I, Balaton G, Balaton P, Vajo Z. The role of dental evaluation and cephalometric analysis in the diagnosis of Williams-Beuren syndrome. Wien Klin Wochenschr. 2005 Mar;117(5-6):226-8. Pubmed PMID: 15875763.

[11]. Torres CP, Valadares G, Martins MI, Borsatto MC, Díaz-Serrano KV, de Queiroz AM. Oral findings and dental treatment in a child with WilliamsBeuren syndrome. Braz Dent J. 2015 May-Jun;26(3):312-6. Pubmed PMID: 26200160.

[12]. Habersack K, Grimaldi B, Paulus GW. Orthodontic orthognathic surgical treatment of a subject with Williams Beuren syndrome a follow-up from 8 to 25 years of age. Eur J Orthod. 2007 Aug;29(4):332-7. Pubmed PMID: 17702793.

[13]. Putrino A, Leonardi RM, Barbato E, Galluccio G. The Association between Ponticulus Posticus and Dental Agenesis: A Retrospective Study. Open Dent J. 2018 Jul 31;12:510-519. Pubmed PMID: 30197690.

[14]. Canargiu F, Erriu M, Piras A, Dibart SN. Modifications of periodontal tissues associated with Williams syndrome. A case report. Minerva Stomatol. 2009 Jul-Aug;58(7-8):375-81. Pubmed PMID: 19633638.

[15]. Yamaguchi T, Shirota T, Adel M, Takahashi M, Haga S, Nagahama R, Nakashima M, Furuhata M, Kamatani T, Maki K. Orthodontic Treatment and Maxillary Anterior Segmental Distraction Osteogenesis of a Subject with Williams-Beuren Syndrome and Isolated Cleft Palate: A Long-Term FollowUp from the Age of 5 to 24 Years. Case Rep Dent. 2017;2017:7019045. Pubmed PMID: 28744380. 